\title{
Education, Democracy and Minority Inclusion
}

\author{
HELENE PRISTED NIELSEN \\ Aalborg University, Denmark
}

This paper starts from the assumption that liberal democratic states, and notably those that show great social diversity, have an interest in retaining as many children as possible within the state's educational system in order to ensure the optimum level of social cohesion. Simultaneously, it is presumed that minority groups within such states may have needs and preferences that require accommodation within existing educational systems. Looking at the examples of Aboriginal and Maori inclusion in the existing educational systems of Western Australia and New Zealand respectively, the paper traces some of the successes and failures of these systems in advancing the (possibly opposing) interests of the liberal state and its indigenous minority groups.

\section{Education and the Liberal Democratic State}

Many western liberal democratic states find themselves confronted by a multicultural reality in that the state has become home to an increasing number of diverse groups with diverse interests and preferences. This reality has ramifications for several aspects of the state apparatus, one of which is the educational system. The juxtaposition between the existing state system and such social diversity is illustrated by the ban on Muslim head scarves for students in French schools and teachers in some German schools, ${ }_{1}^{1}$ and by debates in Denmark about reintroducing compulsory teaching of Christianity. ${ }^{2}$

While the presence of conflict in such juxtapositions in Europe apparently has come as a surprise to many Europeans, other countries have longstanding experiences of combining a liberal democratic state apparatus with ethnic diversity. Two such countries are Australia and New Zealand. While their levels of inclusion and accommodation of ethnic minority wishes can certainly be debated, it is the claim of this paper that Europe might look to these societies for examples of educational systems that both further the democratic aspirations of the liberal state and ensure minority influence on learning and values within the educational system. One of the assumptions 
lying behind this paper is that a minimum level of inclusion is necessary if the liberal state wishes to retain a tolerable degree of social cohesion within society.

From a theoretical perspective, there are two important functions for the educational system within any liberal state attempting to be an inclusive democracy. First of all, the educational sector is itself an arena for debate about values in society, and may as such exert influence on political decisionmaking. Secondly, the primary function of an educational system is arguably to impart to children and students the necessary skills to help them live in democratic societies - and by extension be knowledgeable about different and varying life experiences and values. These two points will both be examined below, with primary focus on the second.

\section{Methodology}

Different venues could have been chosen for generating evidence on how liberal democratic states deal with the challenge of combining the promotion of social cohesion with the inclusion of minority preferences within one and the same educational system. However, Australia and New Zealand, being settler societies with European-derived democratic political systems and simultaneously being acknowledged as multicultural societies, are especially useful examples from a European perspective: there might be lessons to learn. While few European countries have indigenous populations, such groups can arguably be regarded as constituting an inherent, stable and demonstrative presence that co-exists with the wider political culture, thus providing a useful comparative paradigm that can reveal how far established political institutions are willing or able to go to accommodate specific minority preferences.

The paper is based on analyses of two types of empirical evidence collected during 2004 in Western Australia ${ }^{3}$ and New Zealand. The first set of evidence is comprised of policy documents, with a primary focus on the curriculum frameworks of both settings, that reveal the values and visions policy-makers wish to impart to children and adolescents in each of these education systems. This material is supplemented with qualitative data in the form of interviews with people involved in the administrative sectors of the two education systems, including both ministry/departmental employees and school leaders. Thus, the paper does not focus on what is going on in the classroom - although this is certainly relevant for assessing the level of minority inclusion. Rather, it is focused on identifying how the aspirations for social cohesion of the liberal democratic state are borne out at the policy and adminstrative levels. 
Interviewees were selected because of their involvement in administrative functions that addressed questions of Aboriginal or Maori inclusion in the education system in each setting. They were mainly identified from the homepages of the institutions that were deemed to be of interest to the research, such as the Western Australian Department of Education, the Aboriginal Independent Community Schools, ${ }^{4}$ the New Zealand Ministry of Education and the New Zealand Education Institute. Ten people were interviewed, five of them in one group session. Fifteen people were contacted in total, out of whom four declined to answer and one responded with a downright rejection. Interestingly, these five people were all engaged in the Western Australian education system. All respondents signed consent forms.

Interviews were carried out between February and July 2004 and were open-ended in style. ${ }^{5}$ All respondents were given a chance to validate and comment on interview transcripts within a week of the interview, and transcripts were subsequently submitted to a process of open coding based on prevalent themes that emerged during interview sessions (as recommended by Patti Lather ${ }^{6}$ and Strauss and Corbin ${ }^{7}$ ). The four coding categories were 'structure', 'decision-making and influence', 'contact and trust', and 'cultural sensitivity'. These categories all serve to illuminate how the two educational systems contribute to exposing (future) citizens to various beliefs and values, thereby presumably better equipping them to take part in democratic society. While respondents were not promised anonymity, the article attempts to avoid any identifying information.

\section{Policy Documents}

\section{The Curriculum Framework for Western Australia}

The Curriculum Framework ${ }^{8}$ for Western Australia is interesting to examine closely in relation to the aspirations of liberal democracies. It is a policy document with very strong value statements in connection with concepts such as 'democracy', 'tolerance' and 'citizenship'. It was issued in 1998 with the intention of its being fully implemented by 2004. In the words of the document itself, 'It is neither a curriculum nor a syllabus, but a framework identifying common learning outcomes for all students, whether they attend government or non-government schools or receive home schooling. ${ }^{9}$ The emphasis on all students is no accident. The education sector in Western Australia is deeply divided between the non-governmental and the governmental sector, with the former presently 'winning' over the latter in terms of attracting students. This is part of the impetus behind the framework, where the word 'flexibility' is emphasized even from the first 
page, and it is stated from the outset that non-governmental schools need to be allowed more involvement in developing curricula.

The framework itself is claimed to be the product of a consultative process: it is stated that 'seven months of consultation took place' ${ }^{10}$ on the first draft, and that 'a series of public meetings provided opportunities for discussion, debate and the sharing of ideas'. A number of values are specified in the framework, and unlike traditional syllabi, the focus is on outcomes rather than on input. The framework is thus envisaged as more dynamic than a syllabus, in the sense that the outcomes-focused approach leaves greater flexibility for individual teachers and schools.

In Western Australia, there is great variation in the geographical setting, the ethnic and socio-economic background of students, and the financial situations of schools. This fact has undoubtedly played an important role in determining the wording of the document: its flexibility, breadth and inclusiveness are designed to embrace this variation, and, in fact, interview data suggest that non-governmental as well as governmental schools were happy with it. A typical example of how the values and intentions have been worded can be found on p.16: 'While there is a range of value positions in our pluralistic society, there is also a core of shared values'. This is both a gesture to minority viewpoints and an attempt to claim an authority for the values imparted to students. Five such 'core shared values' are summarized, including 'social and civic responsibility, resulting in a commitment to exploring and promoting the common good; meeting individual needs in ways which do not infringe the rights of others; participating in democratic processes; social justice and cultural diversity.. ${ }^{11}$ While these may seem rather general value statements in the sense that they are scarcely indisputable, attempts are also made within the framework to specify more directly what it would mean to impart such values to students.

Particularly interesting from a liberal democratic point of view are the descriptions of values and learning outcomes under the general learning area of 'Society and Environment'. ${ }^{12}$ Here, concepts such as, for example, 'civic responsibility' and 'active citizenship' are widely used, and details are given of how these values are best imparted to children. The learning goal of 'active citizenship' is thus defined on p.252: 'Students demonstrate active citizenship through their behaviours and practices in the school environment, in accordance with the principles and values associated with the democratic process, social justice and ecological sustainability', and further explained as a 'respect for different choices, viewpoints and ways of living; and ethical behaviour and equitable participation in decision making.' ${ }^{13}$

The inculcation of such core abilities in students is arguably essential if an ideal of inclusive democracy is to be approximated within society. In this 
sense, the Western Australian government is promoting a policy that might inspire other educational systems that wish to uphold and encourage inclusive democracy. This point is further supported by the statement that 'The Society and Environment learning area, with its focus on civic responsibility and social competence, has a unique place in the Curriculum Framework. Its basic aim is to give individual students the ability to make reasoned and informed decisions as citizens of a culturally-diverse, democratic society in an interdependent world'. ${ }^{14}$

Several other formulations within the framework support the impression that it promotes an educational system based on values related to inclusive democracy. For example, it is stated as goals that '[Students] will seek to constantly test the integrity of information, recognise the perspectives of all stakeholders and modify conclusions and action where appropriate', ${ }^{15}$ and that ' $[\mathrm{t}]$ hey explore the multicultural nature of Australian society; they analyse a country's response to internal dissent; and they examine civil rights movements' ${ }^{16}$ These qualifications are broken down within the framework so that each stage in the child's development is described in conjunction with the abilities the child is supposed to have achieved at a certain age. Looking at the last stage of development, just before the child leaves compulsory schooling, the description in fact resembles that of the model active citizen - assuming that educational goals are indeed reached. Under the heading 'late adolescence/young adulthood', it is stated that 'Young adults demonstrate an understanding of political, legal and economic structures, particularly in respect of policy generation. They evaluate these systems and policies from social justice and democratic process perspectives and identify ways in which citizens can actively influence the operation of these systems'; and 'Young adults should continue to demonstrate a capacity to review, and, if necessary, modify, their personal perspectives.' ${ }^{17}$ If these are abilities with which Western Australian youth leave school, the future for the state of democratic involvement and inclusion looks bright indeed.

However, even though the wording under the 'Society and Environment' learning area is especially impressive in terms of democratic ideals, one should not be blind to differences between saying and doing. All three respondents from Western Australia involved in Aboriginal participation in the educational system showed great support for the content of the Curriculum Framework, but the two who 'represented' the Aboriginal schooling 'system' (and both objected to the term) also pointed out that in Aboriginal schooling (and amongst other socio-economically pressurised groups) there is often a gap between what one wishes to accomplish and what is in fact achieved or possible to be achieved. Writing an extensive policy document does not do the trick in itself. 


\section{The New Zealand Curriculum in Comparison with the Western Australian Curriculum ${ }^{18}$}

The New Zealand Curriculum was revised in $1997^{19}$ and, according to the foreword, 'It brings together the best of our past curriculum experience, recommendations of the major reviews of education in recent years, and submissions from schools, boards of trustees, and the public, and the views of business and enterprise'. In other words, this document also claims to be the product of a consultative process, and to reflect not only the views of the general public and educational experts (schools and boards of trustees), but also the business community.

As in Western Australia, there is an emphasis on enabling students to participate in democratic society. Part of the goal identified in the curriculum is to enable students to 'develop their potential, to continue learning throughout life, and to participate effectively and productively in New Zealand's democratic society and competitive world economy' (my emphasis). It broadly states that 'The New Zealand Curriculum reflects the multicultural nature of New Zealand society. The school curriculum will encourage students to understand and respect the different cultures which make up New Zealand society' (original emphasis). While the Western Australian Curriculum Framework mentions Aboriginals as holding a particular place in society, they take up a much less prominent place than Maori do in the New Zealand Curriculum. This may partly be the result of the brevity of the New Zealand Curriculum document (23 pages) as opposed to the length of the Western Australian Curriculum Framework (326 pages).

Another major difference of emphasis arguably arises because of the centrality of the Treaty of Waitangi in New Zealand policy documents. ${ }^{20}$ For example, it is stated that 'The New Zealand Curriculum recognises the significance of the Treaty of Waitangi. The school curriculum [at individual schools] will recognise and value the unique position of Maori in New Zealand society. All students will have the opportunity to acquire some knowledge of Maori language and culture' (original emphasis). While 'English is the language of most New Zealanders and the major language of national and international communication', Maori is acknowledged as 'the language of the tangata whenua of New Zealand', 'a taonga under the terms of the Treaty of Waitangi' and 'an official language of New Zealand'.

More or less directly comparable with the learning area of 'Society and Environment' in Western Australia is the learning area of 'Social sciences' in the New Zealand Curriculum, where it is stated that 'A broad understanding of society is essential if students are to take their full place within it as 
confident, informed, and responsible participants. [Students] will examine the ways in which people from different cultures, times, and places make decisions ... Students will be helped to understand their rights, roles, and responsibilities as members of a family and as citizens in a democratic society'. Understanding different ways of decision-making and one's role within units such as the family and society are certainly conducive to participation in democratic society.

As in the Western Australian Curriculum Framework, a number of specific goals or learning outcomes are specified for New Zealand students. Particularly interesting from a democratic perspective are those skills described as 'social and co-operative', where it is stated that students will 'develop good relationships with others, and work in co-operative ways to achieve common goods', 'participate effectively as responsible citizens in a democratic society', and 'develop the ability to negotiate and reach consensus'. If these goals are reached, the future looks bright for democratic inclusion in New Zealand - as in Western Australia.

However, it is expedient to point out the differences between words in a policy document and the reality in a schooling system. In Western Australia, the educational system is strongly divided between governmental and non-governmental schools, often with great socio-economic differences between them. Many Aboriginal children attend poor government schools or independent Aboriginal schools that, despite their non-governmental status, can hardly be compared to rich private schools. In New Zealand, the educational system is generally much more encompassing, and most students, including Maori, attend government schools. While there are Maori students (and parents) who wish for more accommodation of Maori tradition and culture within the educational system, the New Zealand government seems to have been successful in going at least some way towards meeting those wishes and yet retaining a comprehensive schooling system. It is no coincidence that the last chapter in the New Zealand curriculum includes the sentence, 'The statements are sufficiently broad and flexible to allow for local interpretation and elaboration. Such flexibility will empower schools and teachers to design programmes which are relevant to the learning needs of their students and communities'.

\section{Saying and Doing: Other Policy Documents}

Interview evidence suggests that while the values of the New Zealand educational system are expressed in curriculum and other documents, they are supported and supplemented by various additional initiatives that target specific problems and wishes that arise within the educational sector. In Western Australia, there was a sense that 'existing policy' as expressed in 
the long and extremely detailed curriculum policy document was the be-all and end-all of addressing Aboriginal educational needs and wishes.

The application of inclusive policies is illustrated by the example of the Pouwhakataki group, ${ }^{21}$ whose co-ordinator was interviewed in the course of this research. She supplied me with a number of brochures specifically aimed at Maori students and their parents, and pointed to several policy documents, among them 'Strengthening the Ministry's Response to the Education Needs of Maori'. ${ }^{22}$ This specifically addresses the way the Ministry of Education attempts to facilitate the educational wishes of Maori - even the wishes of particular iwi. Under the heading, 'Iwi Education Partnerships Facts Sheet', it is stated that:

Partnerships are relationships between the Ministry of Education and either iwi, or other iwi based and formed Maori education organisations. They are established to help improve the education achievement of Maori children . . . There is no fixed way for the development and establishment of these relationships ... There is no one size and no particular way.

This is evidence of a much more open and dynamic inclusion of particular minority wishes than exists in Western Australia. The Ministry is transparent about its policy in this area, and its attempts to overcome Maori suspicion towards the education system: "They [the partnerships] are helping to overcome the difficulty [sic], often-raised issue by Maori, of finding out what is going on in education'. The very last words on the facts sheet are, 'An important part of this work is to enable a more inclusive approach for thinking about how positive change can be effected within education. This means that the Ministry becomes one part of a wider group who can contribute to achieving better outcomes, rather than the only group.' Compared to evidence from Western Australia, the New Zealand Ministry of Education seems much more ready to devolve responsibility, ${ }^{23}$ which is probably part of the reason why it oversees a much more inclusive educational system.

Writing guidelines for an inclusive educational environment appear to be a profitable line of work in New Zealand, judging by the sheer number. ${ }^{24}$ One such document is 'Better Relationships for Better Learning. Guidelines for Boards of Trustees and Schools on Engaging with Maori Parents, Whanau, and Communities', ${ }^{25}$ which is a detailed set of guidelines for parents on school boards aimed at helping them to be more inclusive when engaging with Maori parents. The guidelines contain both theoretical reasons and practical ideas for greater Maori involvement, and state from the beginning that, 'The choice is not whether schools develop a relationship with Maori communities but what the quality of the relationship will be. ${ }^{26}$ One practical 
way to improve relationships is for interactions to take place kanohi ki te kanohi. ${ }^{27}$ The educational sector is directly identified as having the potential to influence positively all levels of interaction between population groups with presumably different interests. School relationships with local iwi are described as being important because they can provide a model for other local organizations to follow. ${ }^{28}$ Such an ideological position, borne out by actions and practices, supports the theoretical proposition that education is an important vehicle for strengthening inclusiveness within a given democratic society.

\section{Interview Data}

The remainder of this article focuses on interview data from the two settings. While data are not directly comparable due to the different types of involvement of respondents within the two education sectors, all were involved at an administrative level and some points of difference and similarity emerge from analysis. Interviews were conducted with departmental/ministerial officials involved in Aboriginal and Maori education; and a school principal from each setting was also interviewed, but from different types of schools, one a small independent Aboriginal school in a rural community, the other a full government primary school in an urban setting.

The four coding categories used to analyse how the educational systems in each setting contribute to furthering inclusive democracy are: 'structure', 'decision-making and influence', 'contact and trust', and 'cultural sensitivity'. The first category of 'structure' serves as a reminder that data from these settings are not directly comparable, as issues of structure impact heavily on the differing working conditions within the respective educational systems. However, both sets of data illuminate approaches to accommodating minority wishes. The last three categories address the learning goals of the respective curricula, which can be interpreted fundamentally as fostering democratic skills in school leavers. Analysis of the interview data allows us to assess to what extent each educational system exposes students to inclusiveness, tolerance and reflective thinking, as a way of trying to ascertain the realization of democratic goals within each educational system and society at large.

Structure is a prerequisite for making sense of the rest of the data. Interviews with Western Australian informants in particular abound with comments on how the Department of Education, schools themselves, and policies and other structural factors impact on the flexibility and responsiveness of schools. Because the division - or even widening gap - between the governmental and non-governmental education system was 
a prevalent theme in the Western Australian debate, focus is specifically on comments relating to this division.

Data from Western Australia are also undoubtedly heavily coloured by the fact that two of the three interviewees were working outside the government system. Nevertheless, divisions between the governmental and the non-governmental sectors were unquestionably important, judging by the comments of all three respondents, including the one within the Department, as well as debates reported in the daily press. ${ }^{29}$

Aboriginal Independent Community Schools (AICS) were mostly founded in the early 1980s, often in remote Aboriginal communities, where Aboriginal peoples found the government sector inadequate in meeting the educational needs of their children. AICS is a very loose organization, as the main impetus behind these schools was and still is independence. Therefore, individual schools differ quite a lot from each other. One respondent working as a local resource coordinator for these schools remarked that while the schools are to a large extent dependent on existing legislation, they are and wish to remain independent. Individual schools are run by a governing body in the community, and the general policy of the schools is determined by the aspirations of the community rather than by the Department of Education in Perth, which he referred to as 'the Silver City'. While he in this way distanced the AICS from the government system, he also said that presently there was a good level of co-operation between government and AICS, because it had become obvious that these schools 'survived and thrived'.

One of his points was that Aboriginal communities had learned how important it is for the entire community to have a well-functioning school, and this he saw as an important factor in explaining the relative success of these schools. ${ }^{30}$ Another part of the explanation is the funding system. The Western Australian state government funds public schools directly, while private independent schools get a large part of their funding from federal government - this is especially true for the AICS where parent contribution is naturally very limited, as many Aboriginal parents simply do not have the means. Thus the state/federal structure has a huge impact on educational policies in Western Australia, where the state government may pursue a particular line only to see itself overrun by federal money going into the private sector. ${ }^{31}$ The respondent from the Department of Education commented on what the ultimate consequences might be:

And the Federal Government puts significantly more money into the non-government sector, and the difficulty for us is that if we are not careful, the government school system could become a residual system. Where kids tend to move across to the non-government sector, because 
as Western Australians become more affluent, they are prepared to pay a bit more money for education.

New Zealand appears to be a much more homogeneous system, even despite the relatively recent introduction of te kohanga reo and the kura kaupapa system. ${ }^{32}$ This impression was reinforced in a group interview with five people working for the New Zealand Educational Institute (NZEI), ${ }^{33}$ who cited $87 \%$ of Maori children as being in the general system. One of the reasons for maintaining such a high percentage of children within the general education system, despite great ethnic diversity in the country, may be the level of flexibility built into the system. The New Zealand Ministry of Education seems ready to allow for great regional variance and accommodation of iwi wishes. This is an impression further supported by the explanation below, by the principal of the urban school:

Now we have two strands, really; most Maori children are in what I call general education. So they are in schools where the main medium of instruction is English. Then within that there are variations, so within what I call a general education school, you can have bilingual units where the medium of instruction is to a great degree Maori. And then it goes into total immersion, where it is still in a general education setting, but probably the teacher would speak $80-90 \%$ of the time in Maori and instruction is through the medium of Maori. ... Then we have totally separate schools, called kura kaupapa Maori, and their philosophy is underpinned very much by a different world view, a Maori world view.

Readiness to meet the wishes of particular iwi was not only expressed in policy documents and within schools, but was also asserted at a very fundamental level by the respondent working in the Ministry, who referred to it as an obligation ultimately springing from the Treaty of Waitangi: 'What drives all of this is te Tiriti o Waitangi. We as the Crown - what is our responsiveness to the Treaty? That's what really drives it. And from the Treaty comes our legislation'. At a structural level, the Treaty is an important factor when explaining different levels of interaction between indigenous and mainstream groups in the two settings of Western Australia and New Zealand.

The second coding category from interview data, 'decision-making and influence', is in itself a way of illustrating possible democratic processes. Again, data are coloured by the position of respondents. While the AICS principal may appear harsh in his statements about a lack of flexibility within the Department of Education, he readily acknowledged that the government system was trying to allow for more flexibility in the form of devolution 
and greater parent involvement. Nevertheless, he felt that these measures were not taken nearly far enough:

And one of the issues I kept getting feedback from . . . my executive director, was always, 'Stick within policy'. And I kept coming back saying, 'Yeah, but policy isn't working here'. I mean, we are talking about a group where English isn't the first language and where parents have different aspirations for their children, they therefore want to be involved in tailoring of the education to suit their kids' needs. It just didn't work trying to fit a square peg into a round hole.

Government schools are trying to emulate the independent system via local devolution and decision-making. But they will not deal with the fundamental issues of policy, because I think they are fundamentally frightened that schools will be taken over by left-wing hoodlams who will direct the school down the pathway of hippy-ism or something like that! And the standards will begin to decline. My experience was the opposite. That parents involved in decision-making roles actually aspire to great things for their kids.

Judging from interview data as well as from policy documents, the Western Australian government was trying to do something, but it is questionable whether it was the right thing in terms of securing an inclusive future for the educational sector. The interviewee from the Department of Education described a number of measures designed to ensure greater parent involvement (and thereby retention of Aboriginal children) within schools. However, these measures seem rather 'mechanistic', to use one of his own terms in a different application; and he veered off my follow-up question about quality versus quantity measures:

There are huge mechanisms [to ensure parent participation] that are there, and we measure them. We want to see how many Aboriginal people are on decision-making groups, we have particular councils and groups that must be established, every school must have a plan that looks at Aboriginal education within their school plan. Every teacher must undergo cultural awareness training, compulsorily, to ensure that the system is more pro-active in its approach to getting Aboriginal parents involved, but also getting Aboriginal kids through the system.

In contrast, the following statement by one of the people in the group of five from NZEI reflects an attitude towards the political dimension of influence that fundamentally differs from the starting point in Western Australia: 'I think that . . . the issue about why do we participate, why do Maori participate? ... I think that Maori participate because they have 
an expectation'. This quotation is illustrative of the fact that in the New Zealand setting, the drive and demand for inclusive education comes from within the indigenous setting, and is free to emerge there, whereas in the Western Australian examples, there is a srong suggestion that inclusiveness is external and top-down.

The following examples from other people working at NZEI back up the suggestion that in New Zealand the idea of specific Maori influence on educational policies is not just wishful thinking:

I can give you an example: in assessment, for example . . ., there has been a drive in primary schools for compulsory assessment. Well, Maori have been quite outspoken about how disadvantaged they are or have been shown to be through the ways of assessment. Because they are all sort of Pakeha-type tools and a particular way of doing things . . . we have been able to hold back some of the excesses of the government on the basis that it is not inclusive, it disadvantages Maori in schools and it continues a spiral of decline for them ...

I was just going to add - you were talking about earlier grassroots versus policy-driven change, and I was just thinking that an example that popped into my head was during the ' 80 s, the introduction of kohanga reo into New Zealand - early childhood Maori education. And that was really grassroots-driven, the government didn't have a lot of influence or control over that. And you can almost see it slipping under their radar because they thought, 'It is only Maori, and it is only early childhood education'. And it was so successful that it has been built upon in kura kaupapa Maori education.

'Slipping under the radar' is not good democratic practice; rather, it suggests a tactical approach to obtaining impact on educational policies. It also suggests a change occurring by default or proxy rather than by a deliberative openness of policy. Nevertheless, such success stories ${ }^{34}$ may exert a positive influence on the development of co-operative policy initiatives between government and stakeholders, and also point to an expansiveness in the system that allows such co-operation. Based on comments from a Ministry employee, interest in developing joint initiatives between the Ministry and iwi groups can indeed be interpreted as mutual. Speaking about the three or four years of preparation that went into setting up the Pouwhakataki group, he described a procedure that certainly appears to be built on dialogue:

What the Ministry did is it went around and went to tribal groups in New Zealand and said, 'What is it the Ministry can do to help you?' And one of the greatest frustrations was in dealing with the bureaucrats or dealing with the school system. And they said, 'If only we could have somebody that can talk to us in our language, what it means in terms of a board 
of trustees, what are their roles and functions? If somebody could also tell us in terms of the best education for my daughter or for my son. If we can only have someone when I have a problem with the school, the teachers, where I feel it is not teaching my child correctly. Or if there is problem with the administration, if only we can have somebody who can help us to explain and push it through the process.'

However, not all respondents concurred with the impression that the educational policies of New Zealand were the product of dialogic interaction between Maori interests and the Ministry. The principal from the urban primary school pointed to an important factor when arguing that Maori can thank themselves and their level of organization for a lot of their successes within the educational system:

. . . it hasn't been because we have persuaded the powers that be to think our way. It has really been because we've confronted them with the issues and organised and been prepared in some instance to take legal - well, illegal action really. You know, things are getting really, really serious when people are prepared to take illegal action [in reference to parents withdrawing their children from state schools].

Speaking generally about the level of interaction between the population groups over the last couple of decades, she also remarked that 'it wasn't a case of us presenting such compelling arguments the majority decided to change their mind. That's absolutely not how I see it - and this is a personal view. It has changed because they were made to change it, they didn't have a choice really.'

So while there is little doubt that Maori exert greater influence when educational policies are developed in New Zealand than Aboriginals do in Western Australia, it is too hasty a conclusion to draw to say that this is because inclusive democratic mechanisms are in place in New Zealand and not in Western Australia. The relative sizes of the two minority groups also play a role here. But the New Zealand Ministry of Education is geared to include iwi points of view in their planning in a much more direct way than is the case in Western Australia, where the curriculum has been developed with Aboriginal input, but input by those people who themselves have taken action to be heard and come forward. In this regard, the input-seeking approach of the New Zealand Ministry of Education, with a focus on paying visits to iwi and tailoring individual solutions, is rather innovative.

Fittingly, the next category in the analysis is 'contact and trust', and here there is no doubt - either in the Department of Education's employee or in the principal from the independent system - that trust is especially lacking within the Western Australian educational sector in terms of including 
Aboriginal students and their parents. The principal explained the existence of the AICS as being partly a product of lack of contact with and trust in the government system: 'I think that schools like this are in some ways an exhibition of the frustration that people have had in trying to work with the government system'. He also spoke more directly about suspicion:

I didn't understand much about the way the independent system worked at all before I came here. And I think it is a vice versa. So there is this suspicion I suppose. . . . Because the government is suspicious of the independent [schools], because they are losing kids to independents. I think the independent[s] are suspicious of the government system, because they think they are doing better anyway. Which is a pity, because I think both can take from each other and learn from each other.

Referring to historic educational policies, which would not have taken any account whatsoever of creating trust in the Aboriginal community, the Department representative put some of the problems within the education sector down to these policies and the memory of them held by the parents and grandparents of the present generation of Aboriginal school children:

Now, schooling in WA for Aboriginal people commenced in 1965, compulsorily. So it is really, we've only been doing it for 40-odd years. Prior to that it was done by the missions and it was not compulsory schooling . . . Unfortunately, people at my age, between 45 and 50, have had a range of experiences with school, most of which were not desirable, were not good experiences. So consequently their kids, they are actually not quite willing for their kids to stay at school. . . I I mean, most Aboriginal people see government as - in WA, the government took kids away, as you are well aware of, so most Aboriginal people see school as the frontline still, really that school is going to take their kids away. So that in itself is a difficulty that we have. But [also] getting parents to understand why school is there, to trust school teachers.

Even if the goal of an inclusive educational system, in which Aboriginal parents and students trust the system, seems a long way off in Western Australia, initiatives by the New Zealand Ministry of Education prove that it is possible to change this state of affairs- but also that the job will never be quite finished. ${ }^{35}$ Specific programmes like the Pouwhakataki group may solve a certain set of both practical and trust-related problems, but it also seems to be the case that an entire attitude change is needed. A recipe for how this is going to come about is hardly available, but a hint may be found in the following comment on how things have changed within an organization like NZEI in terms of making it more inclusive of Maori viewpoints, rather than simply influencing government policy on behalf of 
Maori: 'Once upon a time I can remember, where anything - you always went to Maori for your answers . . . , and now Maori are saying, "You've got to think this through, you have got to provide the answers for yourself".' Inclusion is thus to be regarded not only as the problem of the minority group, but as an issue to be tackled broadly within the organization - and this principle could be extended to the entire liberal democratic society. At least according to the principal of the urban school, this is an attitude change that has to some extent occurred generally within the New Zealand educational system:

So in general education schools today, there would be very few state and integrated schools where you didn't have some basic form of te reo being spoken or being taught to the children, where their songs or their culture would be included in some form or another. And it will differ from one school to the other in terms of the substance of what is taught and shared in classes, because very much it depends on the confidence and competence of the teacher - and on an attitude change.

Some things, however, are best left to Aboriginal people themselves, according to respondents from Western Australia. The principal from the Aboriginal school clearly felt that in some instances the Department of Education showed a blatant lack of cultural sensitivity when it came to Aboriginal matters - giving the following poignant example of a book which he let me see only the cover of, as it was clearly his opinion that it ought not be shown to me:

I have a copy of a book that was produced about 10 years ago . . . It was never issued. No one knows exactly why this book was produced. This is an Education Department publication . . . No one can look at it, because there are sacred photos in here! There [are] deceased people for starters, and there are a number of photographs that are sacred to Aboriginals. ... The Department is not anthropologists. The Department should just have stuck to what it is meant to do.

The respondent from the Department of Education was also of the opinion that certain Aboriginal practices are best taught outside the school system, in the bush:

I think, one of the things we have to be clear about here is that - I am an Aboriginal person myself - if you want to learn about my culture, I'll take you out in the bush and I will show you what my culture is all about. Because that is where you are going to learn. But if Aboriginal kids are going to learn about Western culture, which they must do, they have to do it in the same environment as non-Aboriginal kids are doing it, and that is in the schooling environment. What we have to do, is to make 
that schooling environment as inclusive of Aboriginal kids as possible. Because what we've found is that that learning environment is not that inclusive. Now, to be able to do that, we have to ensure that there is an Aboriginal voice in the education process, that we, that departments and schools, consult appropriately and get Aboriginal people involved.

Getting Aboriginal people involved is expedient if a goal of exposing children to various life experiences and thereby being able to conduct themselves in a diverse democratic society is to be reached. It makes little difference whether certain cultural aspects are perhaps not really appropriate subjects to be taught in a class setting by an ordinary teacher - inclusion may take different forms.

\section{Education and Democratic Potential}

It makes theoretical sense to view schools as a trial ground for children to practice their engagement skills and to be a place where they will be exposed to other life perspectives and ideas than they might meet at home. Based on interview evidence, a comprehensive integrated and inclusive schooling environment was deemed valuable by most respondents. From an empirical perspective, whether this is in fact a function schools perform can best be evaluated by a long-term comparison of social interaction in societies with a greatly segregated versus an integrated school system.

Viewing the educational system as an important aspect in assessing inclusive practices within society is not a novel idea. The question is whether the above analysis has added information about exactly how and to what extent the educational system makes a contribution. Relating to the question of 'how', it is interesting to note that formulations in the curricula for both settings point to an awareness of educating future citizens who should ideally be able to conduct themselves in societies with people holding a variety of beliefs and preferences. Relating to the question of 'extent', the difference between the relative successes of the governmental education systems points to what might potentially be damaging implications for the level of inclusion within the Western Australian educational system. Risking a split between the well-off and children whose parents for various reasons do not endorse government schooling does not bode well for a system which professes to aim to educate all children to become 'active citizens' and be able to engage profitably with people of other values and preferences.

On the question of 'extent', evidence shows that the New Zealand Ministry of Education in particular has been very open in trialling new models of education and listening to the needs and wishes of different parental groups and their school children. This does not mean that control is relinquished, but rather that diverging interests are kept within the range of the Ministry's 
working. Whether one wishes to interpret this as 'control', or merely as an effort to span widely, is probably a question of temperament as much as ideology. In the words of one respondent commenting on te kohanga reo:

Well, kohanga reo started off as a break-away movement and an ethic to try and foster Maori language. . . . But now it has become integrated into the system, and it gets government funding and all the rest of it. . . . by meeting certain criteria they can access educational funding, and that of course brings them into the system, and they get assessed alongside every other institute of like kind.

Maori parents were at one point taking illegal action and removing their children into Maori language immersion schools. Now those schools under the kaupapa Maori ideology have become a separate branch within the governmental system. However, in the words of Bishop and Glynn, 'Kaupapa Maori is a discourse that has emerged and is legitimated from within the Maori community. Kaupapa Maori assumes the taken-for-granted social, political, historical, intellectual and cultural legitimacy of Maori people, in that it is a position where "Maori language, culture, knowledge and values are accepted in their own right". ${ }^{36}$ The words 'from within' have been emphasized in this quotation, because even if the kura kaupapa schools now come under the aegis of the Ministry, they still ultimately spring from Maori interest and can therefore be regarded as proof of the Ministry's willingness to enter into dialogue with Maori. Fleras and Spoonley cite exactly the kura kaupapa schools as an instance of tino rangatiratanga in practice - as promised to Maori in the Treaty of Waitangi. ${ }^{37}$ They conclude: 'in securing a pattern of constructive engagement that sharply curbs state jurisdiction while enhancing Maori models of self-determination, kura kaupapa Maori serves notice that rangatiratanga rights are not to be taken lightly in postcolonising Aotearoa'. ${ }^{38}$

There is no question about the fact that the Treaty of Waitangi heavily influences Crown/Maori relations in New Zealand, and that the Aboriginal people of Western Australia cannot refer to an historic document that protects their interests within - for example - education. This deficit, however, hardly precludes the possibility of 'securing a pattern of constructive engagement', provided genuine interest really exists. Both the lack of a treaty as well as the historical suspicion towards any government agency adversely impact on Aboriginal abilities to make the most of the educational system and thus secure themselves a place within society.

\section{Conclusion}

Based on data presented here, New Zealand fares better than Western Australia in creating an inclusive educational environment that furthers (liberal) democratic values and social cohesion. This conclusion is based on 
a number of indicators. The New Zealand Curriculum leaves many more decisions to individual schools. But what is more important in this connection is the fact that the New Zealand Ministry of Education continually develops new programmes in co-operation with stakeholders, and is very proactive in terms of seeking input to policies and frameworks. ${ }^{39}$ The Ministry is geared to tailor individual solutions to iwi. While one NZEI representative suggested that te kohanga reo was slipped under the Ministry's radar in the early 1980s, this does not seem a likely scenario in post-2000 policies. The Ministry is attuned to change, whether one would interpret this as first and foremost a democratic gesture, or more as a question of wishing to retain control. However, it would seem cynical and naïve to consider this an issue of control.

While the Western Australian Curriculum Framework is an impressive policy document in terms of articulating ideals of 'democracy' and 'active citizenship', it is in one perspective a rhetorical policy document; and while it has been developed in co-operation with stakeholders outside the state government system, those stakeholders are to a large extent those identified by the Department of Education itself. Furthermore, its sheer comprehensiveness reduces the ability of individual schools to manoeuvre, and it would seem a more pragmatic stance to emulate New Zealand Ministry of Education practices when engaging with Aboriginal parents and other stakeholders within the educational system, for example, by devolving responsibility and creating local solutions. While the comment that at the moment the Western Australian Department of Education was trying to 'fit a square peg into a round hole' may be a little harsh, greater room for individual (tribal/geographic) wishes may go a long way to ensuring future success also for the state government schooling system. The first impediment here, however, is the pronounced lack of trust between the government and many Aboriginals, which was pointed out by stakeholders both within and outside the governmental system. This is a question that needs to be addressed directly, and one starting point might be to develop closer co-operation with the already established non-governmental schools within the AICS system. However, no easy solutions are available, and the federal/state structure in Australia further complicates the relationship between governmental and non-governmental schools in Western Australia and inhibits direct change.

Concerning the democratic potential inherent in fostering an inclusive educational environment, it should also be kept in mind that not only may schools have an educating function in imparting to children an ability to express their opinions and preferences and listen to those of others, but also their parents, teachers, board members and members of the communities in 
which they live may gain experiences in those fields as well, through cooperative practices developed in connection with school work..$^{40}$ If such ideals are brought to life within the schooling environment, it is very important to include education in assessing democratic practices and minority inclusion within society. In this sense, experiences from Australia and New Zealand could prove very useful indeed for European countries that are gradually coming to terms with a need to revise their educational strategies for a future of diverse yet cohesive societies.

1 See Thomas Smith Rudolf, 'Debating Scarfs in Europe', Paper presented at the conference 'What's the Culture in Multiculturalism - What's the Difference of Identities? Contesting the Future of Equality, Secularism, and National Solidarity', Aarhus University, Denmark, 22-24 May 2003. Accessed 30 March 2007 at: www.politicaltheory.dk/conference/res/ papers/5202003143807Debatting\%20Scarfs\%20in\%20Europe\%20(Rudolf).pdf.

2 This debate has been recurring for a number of years, and resurfaced as recently as April 2007 as the supporting party Dansk Folkeparti (the Danish People's Party, a rightwing nationalist party) for the coalition government called for the reintroduction of a compulsory devotional morning song, and the teaching of Christianity and Latin in all Danish primary schools.

3 Because Australia is such a large country with a federal structure that devolves major responsibility for education to individual states, Western Australia was chosen as a focus because of its comparatively high percentage of indigenous inhabitants.

4 For the respective homepages, see Department of Education: www.det.wa.edu.au, New Zealand Ministry of Education: www.minedu.govt.nz, New Zealand Education Institute: www.nzei.org.nz, and Aboriginal Independent Community Schools: www.aics.wa.edu.au. All homepage addresses verified 30 March 2007.

5 As described in Steiner Kvale, InterView. En introduction til det kvalitative forskningsinterview [Introduction to qualitative research interviews], 8th edition, Copenhagen, 2002, 1994.

6 Personal communication about the working processes involved in Patti Lather and Chris Smithies, Troubling the Angels: Women Living with HIV/AIDS, Boulder, Colorado, 1997.

7 Anselm Strauss and Juliet Corbin, Basics of Qualitative Research. Techniques and Procedures for Developing Grounded Theory, London, 1998, pp.57-73 and 101-22.

8 The Curriculum Council, Western Australia, 'Curriculum Framework for Kindergarten to Year 12 Education in Western Australia', 1998.

9 Ibid., p.6.

10 Ibid., p.7.

11 Ibid., p.16.

12 Ibid., p.249-88.

13 Ibid., p.261.

14 Ibid., p.251.

15 Ibid., p.255.

16 Ibid., p.258.

17 Ibid., p.278. 


\section{Education, Democracy and Minority Inclusion}

18 The New Zealand Curriculum Framework, accessed 15 June 2004 at: http://www.tki.org. nz/r/governance/nzcf/index_e.php (23 pages in total). Unfortunately, no page references are available as the online text is not page-formatted.

19 Russell Bishop and Ted Glynn, Culture Counts: Changing Power Relations in Education, London and New York, 2003, p.135.

20 At least those drawn up after 1986, according to Augie Fleras and Paul Spoonley, Recalling Aotearoa: Indigenous Politics and Ethnic Relations in New Zealand, Auckland, 1999, p.121.

21 Pouwhakataki is a group of people employed by the New Zealand Ministry of Education to work locally with Maori groups to help them get the most out of the education system. See 'Who are the Pouwhakataki?', information brochure about the Pouwhakataki group from the New Zealand Ministry of Education, published by the Ministry of Education, Wellington. Publication date unknown, ministerial identification number EDU0946-10/0312K HU-1053-TM.

22 'Iwi Partnerships Facts Sheet', published by Ministry of Education. Accessed 27 April 2005 at: www.minedu.govt.nz, ddocument id 7394.

23 According to Bishop and Glynn, the Ministry of Education has changed its policies rather dramatically to be more inclusive of Maori during the 1990s - see Culture Counts, especially pp.96-98.

24 Moreover, the media do in fact show some interest in these policy documents, for example, in the article 'Maori education gets high priority', Dominion Post, 31 May 2004, p.11 which comments on the Ministry of Education's Statement of Intent 2004-2009. See Ministry of Education, 'Statement of Intent 2004-2009'. Accessed 12 August 2005 at: www.minedu.govt.nz, document id 9644.

25 'Better Relationships for Better Learning. Guidelines for Boards of Trustees and Schools on Engaging with Maori Parents, Whanau, and Communities', Ministry of Education, Wellington, 2000. Accessed 27 April 2005: at www.minedu.govt.nz, document id 4231.

26 Ibid., p.7.

27 Ibid., p.10.

28 Ibid., p.25.

29 A rough count of articles from the only state-wide Western Australian newspaper, The West Australian between 9 February and 8 April 2004 shows 52 stories on the school system, out of which 31 focused on public/private schooling. A distant second prioritized subject was the lack of male teachers within the public school system. See, for example, Charlie Wilson-Clark, 'Parents turn from State Schooling', The West Australian, 25 February 2004, p.17.

30 Relative, because most of the schools are still battling heavy socio-economic and health disadvantages. One school on the AICS homepage cited $85 \%$ of their pupils as having a hearing disorder due to the simple infection otitis media which, if not treated with penicillin, can permanently damage a child's hearing abilities. Accessed 3 February 2005 at: www.aics.wa.edu.au.

31 At the time of conducting the interviews, every single state government was Labor-led, while the federal government was Conservative.

32 Te kohanga reo literally means 'language nest' and is a preschool available to Maori and other children where interaction takes place in te reo Maori. It was introduced in 1982. Subsequently, it has been followed up by the kura kaupapa schools, which are schools built on 'Maori philosophy and principles', Bishop and Glynn, Culture Counts, p.61.

33 See www.nzei.org.nz, accessed 7 July 2005. 


\section{Journal of New Zealand Studies}

34 'Success' both in the sense of having an interest converted into a political decision, but also success in the sense that 'The success of the language nests [te kohanga reo] has been phenomenal', Bishop and Glynn, Culture Counts, p.74.

35 This statement is based on a premise that means that I reject the conclusions of Robert Putnam in Making Democracy Work, Civic Traditions in Modern Italy (Princeton, 1993) and instead find greater credibility in the work of Marc Hooghe and Dietlind Stolle, eds, Generating Social Capital: Civil Society and Institutions in Comparative Perspective, New York, 2003.

36 Bishop and Glynn, Culture Counts, p.63, my emphasis. The internal reference is to G.H. Smith, 'Tane-nui-a-rangi's Legacy . . . Propping Up the Sky: Kaupapa Maori as Resistance and Intervention', Paper presented at the New Zealand Association for Research in Education/Australia Association for Research in Education joint conference, Deakin University, November 1992.

37 'Tino Rangatiratanga in Practice: Kura Kuapapa Maori', in Fleras and Spoonley, Recalling Aotearoa, pp.31-37.

38 Fleras and Spoonley, Recalling Aotearoa, p.37.

39 In further support of this observation, I would like to draw attention to the following entry from the March 2007 electronic newsletter by the New Zealand Race Relations Commissioner, acknowledging a series of 'positive contributions to New Zealand race relations': 'Ministry of Education: For the Māori in the Mainstream Curriculum. Launched on Race Relations Day [21 March 2007] by the Minister of Māori Affairs and the Race Relations Commissioner, this is the first ever curriculum for Māori language in mainstream schools. It will provide a foundation for all students over time to have the opportunity to learn te reo Māori in mainstream primary and secondary schools. . . . It was noted that the challenge for the future will be to progressively provide resources for all schools and to train teachers to deliver this curriculum as well as training enough teachers and producing enough resources for Māori immersion schooling' (www.hrc. co.nz/home/hrc/newsandissues/onthebrightsidemarch2007.php).

40 See, for example, the idea(1)s expressed in 'Better Relationships for Better Learning. Guidelines for Boards of Trustees and Schools on Engaging with Maori Parents, Whanau, and Communities', Ministry of Education, 2000. Accessed 27 April 2005 at: www. minedu.govt.nz. 